9. Koupil I, Mann V, Leon DA, Lundberg U, Byberg L, Vagero D. Morning cortisol does not mediate the association of size at birth with blood pressure in children born from full-term pregnancies. Clin Endocrinol (Oxf). 2005;62:661-6.

10. Jones A, Godfrey KM, Wood P, Osmond C, Goulden P, Phillips DI. Fetal growth and the adrenocortical response to psychological stress. J Clin Endocrinol Metab. 2006;91:1868-71.

11. Schmidt NA. Salivary cortisol testing in children. Issues Compr Pediatr Nurs. 1998;20:183-90.
12. Hanrahan K, McCarthy AM, Kleiber C, Lutgendorf S, Tsalikian E. Strategies for salivary cortisol collection and analysis in research with children. Appl Nurs Res. 2006;19:95-101.

13. Dressendörfer RA, Strasburger CJ, Bidlingmaier F, Klug I, Kistner A, Siebler T, et al. Development of a highly sensitive nonisotopic immunoassay for the determination of salivary 17-hydroxy-progesterone: reference ranges throughout childhood and adolescence. Pediatr Res. 1998;44:650-5.

\title{
Breastfeeding and Baby-Friendly Hospital Initiative: more important and with more evidence than ever
}

\author{
Miriam H. Labbok*
}

B survival, and has been so recognized for millennia. With the commercialization of formula in the 20th century, an unparalleled experiment was about to be visited upon mothers and children. In her treatise on "Milk and murder" in 1939, Dr. Cicely Williams outlined the dangers of disrupting breastfeeding: "If your lives were embittered as mine is, by seeing day after day this massacre of the innocents by unsuitable feeding, then I believe you would feel as I do that misguided propaganda on infant feeding should be punished as the most criminal form of sedition, and that those deaths should be regarded as murder." (Many years later, I was privileged to study with Dr. Williams, which certainly contributed to my understanding of the need for breastfeeding and my dedication to the mother/child dyad.)

Nonetheless, commercial formula manufacture became a successful industry, aggressively marketing to the public, health care providers, nurses and pediatricians, alike. As

* MD, MPH, FACPM, IBCLC, FABM, Professor and Director, Center for Infant and Young Child Feeding and Care, Department of Maternal and Child Health, School of Public Health, University of North Carolina, Chapel Hill, NC, USA.

Suggested citation: Labbok M. Breastfeeding and Baby-Friendly Hospital Initiative: more important and with more evidence than ever. J Pediatr (Rio J). 2007;83(2):99-101.

doi:10.2223/JPED.1606 women in industrialized settings began to enter the labor market in larger numbers, the market for time-saving commercial food products increased. Formula became known as 'modern', and risks associated with the lack of breastfeeding were compensated for by isolating infants and early weaning. Young women did not grow up seeing breastfeeding, nor learning of it from others. As a result, by mid-century, the maternal skills associated with initiation and maintenance of breastfeeding were in danger of being lost in many settings around the world.

The Baby-Friendly Hospital Initiative (BFHI) came about as the result of several concurrent health and health policy events. Following the endorsement of the International Code of Marketing of Breast-Milk Substitutes in the early 1980s, there was increasing recognition that, after nearly 50 years of heavy formula marketing, health care providers and, often, women themselves no longer retained the skills associated with successful breastfeeding. Mr. James Grant, Director of UNICEF, initiated a tightly directed campaign to reduce child mortality: GOBI - Growth monitoring, oral rehydration, breastfeeding and immunization. Subsequently, the Ten Steps to Successful Breastfeeding were developed by the World Health Organization (WHO) and the United Nations Children's Fund (UNICEF) in a very collaborative and comprehensive manner in order to provide a simplified outline for 
health care professionals, especially those working in maternities, as to the basic elements of breastfeeding support.

Later in that decade, the technical staff of UNICEF, WHO, the United States Agency for International Development (USAID) and the Swedish International Development Cooperation Agency (Sida) began to meet to discuss how implementation of programs to improve breastfeeding might proceed. Following several targeted working conferences ${ }^{1}$ and a technical consultation held at $\mathrm{WHO}^{2}{ }^{2}$ a meeting was held at the UNICEF Innocenti Centre in Florence, Italy, the output of which became known as the Innocenti Declaration. That Declaration called for implementation of the Code and the Ten Steps, as well as maternity protection and other innovative law and regulation, with the goal that all maternities worldwide would achieve the Ten Steps by 1995.

History tells us that that goal was a bit optimistic. However, history, along with a growing literature of well executed studies, is also telling us that the Innocenti Declaration was, indeed, an excellent roadmap. The Baby-Friendly Hospital Initiative, the program that was designed to implement the Ten Steps, is consistently shown to have profound impact at the individual hospital level. Perhaps the best known demonstrations of this fact are PROBIT (Promotion of Breastfeeding Intervention Trial) studies ${ }^{3}$ which demonstrated not only that the Ten Step approach would increase breastfeeding, but also that this increase is demonstrably associated with a variety of positive health outcomes. One aspect of BFHI - the 18 hours, or approximately 3 days, of training, including practical sessions and counseling skills, are effective in changing not only hospital practices, but also the knowledge of health workers and breastfeeding rates. Both of these findings, i.e., improved health worker skills and improved breastfeeding rates, ${ }^{4,5}$ were intended outcomes of the BFHI. Through regular review of the numbers of maternities that were ever designated as baby-friendly facilities, UNICEF reports that, by the end of 2005, nearly 20,000 maternities had been so designated at some point in time. ${ }^{6}$ There are no central records of how many of these facilities are currently compliant with the principles of BFHI.

There are a limited number of studies that attempt to show the impact of BFHI at the population level. Recently, a study of the impact of BFHI in Switzerland ${ }^{7}$ confirmed that BFHI is associated with improved outcomes. They also addressed the issue of self-selection, i.e., the concern that the $\mathrm{BFH}$ have better outcomes only because women who wish to breastfeed choose to deliver at these sites. They found that the duration of exclusive and full breastfeeding was significantly longer if delivery occurred in a baby-friendly hospital with high compliance with the UNICEF guidelines. ${ }^{8}$ This study confirmed that it is indeed the practices called for in BFHI, rather than just the 'label' of $\mathrm{BFH}$, that are associated with the positive outcomes.
Perhaps we should take one step back, and ask ourselves: Is breastfeeding worth the effort today? Since Innocenti, exclusive breastfeeding in the first 6 months of life has increased substantially, from 34 to $41 \%$. This increase may well have been a major contributor to the concurrent decline in child mortality in developing countries, which has been well documented. As to the importance of breastfeeding in this regard, if there had been any doubt since the technical background for the Innocenti Declaration was assembled, these concerns should have been substantially set aside with the publication of the Lancet Child Survival series ${ }^{9}$ and the recent meta-analyses on the long-term impacts of breastfeeding. ${ }^{10}$ The Lancet series presented a listing of those interventions that could reduce child mortality, as called for in the Millennium Development Goals, especially Goal 4. The intervention found to have the greatest potential for saving lives was exclusive breastfeeding, with continued breastfeeding in the first year of life. This one intervention alone would prevent about 1 of 7.5 current child deaths, offering a programmatic key to the achievement of this Millennium Goal. More recently, the WHO meta-analysis on the long-term health impact of breastfeeding clarified the significant risks associated with the lack of breastfeeding.

Nonetheless, the global community has not as yet seen this as a signal to redouble proven efforts; program and funding decision-makers continue to challenge these studies and the many evaluations that document the impact of breastfeeding, and that the BFHI increases breastfeeding rates; it is indeed more difficult to demonstrate the costs and effects of attempting to create a major socio-behavioral change in a simple "dollar for outcome" equation than it is to document the cost of delivering a commodity, such as a pill or a bed-net, for example. Hence the cost-effectiveness and cost-benefit analysts have tended to shy away from committing themselves when it comes to the cost-benefit of BFHI. As a result, major international efforts on child survival today seem to be shifting support for breastfeeding from the health system to the community, despite the impact that has been achieved, and will continue to be achieved, wherever BFHI is initiated.

One of the major stumbling blocks in establishing the cost-effectiveness of BFHI has been the limited number of studies that provided population-based data on this intervention. The study by Antônio Caldeira and Eduardo Gonçalves, ${ }^{11}$ presented in this issue, entitled, "Assessment of the impact of implementing the Baby-Friendly Hospital Initiative" provides us with data on a population-based initiative in the urban area of Montes Claros. The increases in exclusive breastfeeding achieved, from 25 to $40 \%$ in each of the first 5 postpartum months, cannot be explained away by time or other national-level interventions.

In addition, this article demonstrates that a well planned activity such as this, which ensures that an entire population 
area receives this coverage, will have an impact not only on initiation and short-term breastfeeding, but also would seem to have a sustained impact at the community level, ensuring longer durations of both exclusive and any breastfeeding.

Today, the BFHI is 15 years old. At this age, it could be viewed as in its adolescence - growing, changing, and revising itself to meet the changing needs of adaptation, expansion, integration and sustainability. In Brazil, as in most countries worldwide, it has contributed to the steady increase in full and exclusive breastfeeding. ${ }^{12}$ Therefore, UNICEF and WHO have revised both the guidance for implementation of BFHI at the national and hospital levels, as well as the materials for decision-makers, training, and evaluation. These materials are available for use and for final review, and are expected to be finalized this year.

The four program pillars - legal protection for maternity protection and against aggressive marketing of commercial formula, health care worker training and BFHI, and community support - are needed to continue the positive trends in exclusive breastfeeding we have seen since 1990 . With the new materials and the new data available, BFHI should continue to receive our support and attention.

\section{References}

1. Proceedings of the Interagency Workshop on Health Care Practices Related to Breastfeeding. December 7-9, 1988. Washington, DC. Int J Gynaecol Obstet. 1990;31 Suppl 1:1-191.

2. Saadeh R, Labbok M, Cooney K, Koniz-Booher, eds. Breastfeeding: the technical basis and recommendations. Geneva: WHO; 1993.
3. Kramer MS, Chalmers B, Hodnett ED, Sevkovskaya Z, Dzikovich I, Shapiro S, et al.; Promotion of Breastfeeding Breastfeeding Intervention Trial (PROBIT): a randomized trial in the Republic of Belarus. JAMA. 2001;285:413-20.

4. Valdés V, Pugin E, Labbok MH, Pérez A, Catalan S, Aravena R, et al. The effects on professional practices of a three-day course on breastfeeding. J Hum Lact. 1995; 11:185-90.

5. Cattaneo A, Buzzetti R. Effect on rates of breast feeding of training for the baby friendly hospital initiative. BMJ. 2001;323:1358-62.

6. The United Nations Children's Fund Innocenti Research Centre. 1990 - 2005: Celebrating the Innocenti Declaration on the Protection, Promotion and Support of Breastfeeding - Past Achievements, Present Challenges and Priority Actions for Infant and Young Child Feeding. Innocenti Insights, 2007. UNICEF BFHI records are updated regularly, 2005/2006. http://www.waba.org.my/bfhi.htm, and breastfeeding trends are assessed regularly. http://www.childinfo.org.

7. Merten S, Dratva J, Ackermann-Liebrich U. Do baby-friendly hospitals influence breastfeeding duration on a national level? Pediatrics. 2005;116:e702-8.

8. Philipp BL, Malone KL, Cimo S, Merewood A. Sustained breastfeeding rates at a US baby-friendly hospital. Pediatrics. 2003;112(3 Pt 1);e234-6.

9. Jones G, Steketee RW, Black RE, Bhutta ZA, Morris SS; Bellagio Child Survival Study Group. How many child deaths can we prevent this year? Lancet. 2003;362:65-71.

10. Horta B, BahI R, Martines J, Victora C. Evidence on the long-term effects of breastfeeding - systematic reviews and meta-analyses. WHO; 2007. http://www.who.int/childadolescent-ealth/New_Publications/ NUTRITION/ISBN_92_4_ 159523_0.pdf.

11. Caldeira AP, Gonçalves E. Assessment of the impact of implementing the Baby-Friendly Hospital Initiative. J Pediatr (Rio J). 2007;83:127-32.

12. Rea MF. Reflexões sobre a amamentação no Brasil: de como passamos a 10 meses de duração. Cad Saude Publica. 2003;19(Supl 1):S37-45. 